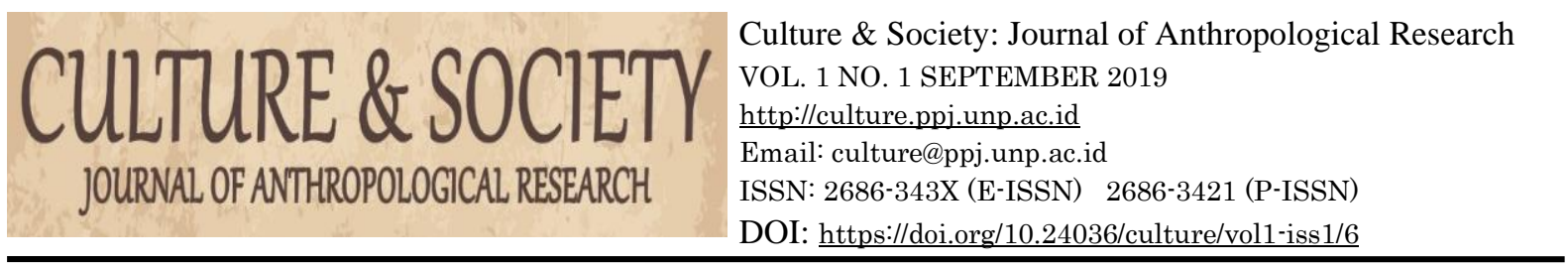

\title{
Perilaku Gaya Hidup Hedonisme di Kalangan Mahasiswa Kurang Mampu Fakultas Ilmu Sosial UNP
}

\author{
Rika Hidayati ${ }^{1}$ Ikhwan Ikhwan ${ }^{2}$ \\ ${ }^{1,2}$ Universitas Negeri Padang \\ Email: rikahidayati19@gmail.com, ichone.in@gmail.com
}

\begin{abstract}
Abstrak
Riset ini dilatarbelakangi oleh ketertarikan peneliti dalam melihat maraknya perilaku gaya hidup hedonisme di kalangan mahasiswa kurang mampu di Fakultas Ilmu Sosial UNP. Riset ini memiliki tujuan untuk memahami bagaimana perilaku hedonisme di kalangan mahasiswa kurang mampu FIS UNP. Riset ini di kaji menggunakan teori masyarakat konsumsi dari Jean Baudrillard. Baudrillard berasumsi bahwa masyarakat mengkonsumsi suatu barang atau jasa bukan lagi dilihat pada pemenuhan kebutuhan (nneds), tetapi lebih kepada pemenuhan hasrat (desire). Metode yang dipakai dalam riset ini adalah pendekatan kualitatif tipe deskriptif, teknik pemilihan informan snowball sampling dan jumlah informan sebanyak 10 orang. Pengumpulan data dibuat dengan teknik observasi, wawancara, dan pengumpulan dokumen dan dikaji menggunakan teknik analsis data dari Miles dan Huberman. Hasil riset ini menyatakan Perilaku Gaya Hidup Hedonisme Di Kalangan Mahasisswa Kurang Mampu FIS UNP ditunjukkan melalui kegiatankegiatan sebagai berikut: (1) shopping; (2) Nongkrong di cafe; (3) nonton bioskop; (4) karaoke; (5) jalanjalan/refreshing.
\end{abstract}

Kata Kunci: Perilaku Sosial, Gaya Hidup Hedonisme, Mahasiswa

\begin{abstract}
Research is motivated by the interest of researchers in seeing the rise of behavioral style of life of hedonism in the students less capable in the Faculty of Sciences of Social UNP. Research it has the purpose to understand how the behavior of hedonism in the students less able to FIS UNP. Research is in the review using theory consumption society of Jean Baudrillard. Baudrillard assumes that society consumes an item or service is not longer seen on the fulfillment of the needs (nneds), but more to the fulfillment of desire (desire). The method that is used in research this is the approach of a qualitative type of descriptive, technical election of informant snowball sampling and the number of informants as many as 10 people. The collection of data is made with the technique of observation, interviews, and collecting documents and assessed using the technique of the analysis of data from Miles and Huberman. The results of the research have expressed Behavioral Style Living Hedonism Di Among Mahasisswa Less Able FIS UNP demonstrated through activities as follows: (1) shopping; (2) Hang out at the cafe; (3) watching a movie theater; (4) karaoke; (5) sightseeing / refreshing. Keywords : Social Behavior, Style Living Hedonism, Students
\end{abstract}

\begin{tabular}{l|l|l|} 
Received: August 29, 2019 & Revised: September 4, 2019 & Published: September 5, 2019 \\
\hline
\end{tabular}

Culture \& Society: Journal of Anthropological Research Vol. 1, No. 1, Th. 2019

2686-343X (E-ISSN) 2686-3421 (P-ISSN)

Copyright (C) 2019, by Author. 


\section{Pendahuluan}

Mahasiswa merupakan bagian dari masyarakat sebagai generasi penerus bangsa yang berperan untuk memajukan serta dapat bersaing dengan Negara lain dalam segala aspek seperti ilmu pengetahuan maupun teknologi informasi (Destiana, 2018). Kemajuan pada aspek ilmu pengetahuan dan teknologi memberikan pengaruh pesat terhadap perubahan gaya hidup manusia. Kondisi tersebut mengakibatkan kebanyakan orang mengikuti trend yang sedang berlaku, sehingga menimbulkan permasalahan baru bagi kelangsungan hidupnya. Perkembangan zaman sangatlah berkaitan dengan perubahan pada gaya hidup seseorang. Hal itu sangatlah wajar karena tiap-tiap orang cenderung menginginkan kehidupan yang lebih baik. Gaya hidup merupakan suatu hal yang terpenting bagi sebagian orang karena menganggap gaya hidup sebagai jati diri yang membedakannya dengan orang lain.

Gaya hidup seseorang diterapkan dalam kegiatan hidup sehari-hari baik berupa aktifitas, minat maupun opini. Aktifitas yang dilakukan seseorang berkaitan dengan cara seseorang tersebut dalam mempergunakan waktunya. Minat merupakan suatu hal menarik yang bisa membuat seseorang memikirkan jati diri serta lingkungan sekitarnya. Pencarian jati diri oleh mahasiswa dapat dilihat melalui perilaku yang diperlihatkan dalam kehipan yang ditampilkan (Riadhah \& Rachmatan, 2016). Seseorang dikatakan memiliki gaya hidup yang wajar jika hal tersebut tidak membuatnya melakukan kepentingan akademik dan pekerjaan. Saat ini kebanyakan orang lebih mengutamakan aspek gaya hidup dibandingkan hal lainnya, mereka mementingkan kesenangan bahkan mereka rela mengorbankan apapun demi mendapatkan kesenangan tersebut tanpa memikirkan efek yang ditimbulkan oleh hal yang mereka inginkan. Kecenderungan inilah yang saat ini kita kenal dengan istilah gaya hidup hedonis atau gaya hidup yang mementingkan kesenangan yang identik dengan materi. Remaja sebagai generasi penerus bangsa pada kenyataannya saat ini juga ikut terbawa arus gaya hidup hedonis, terutama di kalangan mahasiswa. Hal ini terjadi karena mahasiswa mempunyai peluang yang sangat tinggi dalam mengikuti trend yang terjadi saat ini dibandingkan tingkatan remaja lainnya (Lukitsari, 2016).

Mahasiswa yang saat ini disibukkan dalam hal mencari jati diri sangat berpeluang untuk menjadi sasaran bagi kaum elit kapitalis. Mahasiswa cenderung mengikuti trend pasar sehingga dapat menjadi lading penghasil uang bagi pasar. Kecenderungan tersebut bisa mengendalikan dirinya sehingga melahirkan sifat hedonism. Menurut Amstrong (Trimartati, 2014) yang dimaksud dengan gaya hidup hedonis ialah sebuah pola hidup yang berorientasi kepada hal mencari kesenangan hidup, baik berupa kebiasaan senang manghabiskan waktu di luar rumah bersama teman-teman, cenderung bermain, senang dengan keramaian kota, member barangbarang mahal dan selalu ingin menjadi pusat perhatian orang lain. Menurut (Lukitsari, Viska. 2016) Fenomena gaya hidup hedonis ini dtinjukkan kalangan mahasiswa dalam hal kebiasaan mahasiswa dalam menghabiskan waktu dan menggunakan uang saku pemberian orang tua mereka. Menurut Kotler (nur ambadra dewi, 2018) gaya hidup seseorang dipengaruhi oleh dua faktor yaitu faktor internal (yang berasal dari dalam diri) dan faktor eksternal (yang berasal dari luar atau lingkungan sekitar). Gaya hidup identik dengan kebiasaan seseorang dalam mengatur kehidupannya, sikap di depan umum, serta keinginan untuk mendapatkan status sosial yang lebih tinggi dari orang lain melalui symbol-simbol sosial. Gaya hidup memberikan pengaruh yang sangat besar terhadap manusia sesuai dengan tindakan sosial di masyarakat. Menurut Hurlock (Nisrima, Muhammad, \& Erna, 2016) menyatakan perilaku seseorang ditentukan oleh lingkungan sekitar dimana seseorang tersebut berada.

Adapun pencetus dari paham hedonisme itu sendiri adalah Filsuf Epicurus yang memaknai bahwa hedonisme itu perasaan acuh tak acuh terhadap lingkungan di luar komunitas mereka. Filsuf Epicurus juga mengatakan jika kesenangan dan kenikmatan adalah tujuan utama dalam hidup yang ditujukan agar terpenuhinya ketenangan batin (Simamora, 2014).

Maraknya fenomena gaya hidup hedonis sangat berpengaruh kepada mahasiswa. Gaya hidup hedonis di kalangan mahasiswa sangat unik, karena tidak semua mahasiswa yang bergaya 
hidup hedonis berasal dari kalangan keluarga berekonomi menengah keatas atau yang tergolong mampu. Sebagian mahasiswa tersebut berasal dari latar belakang keluarga berekonomi menengah kebawah. Namun perilaku yang ditampilkan mahasiswa dengan dengan tingkat ekonomi menengah kebawah hampir sama dengan mahasiswa yang memiliki ekonomi mapan. Perilaku hedonis di kalangan mahasiswa berekonomi pas-pasan sangatlah terlihat aneh dengan sejumlah kegiatan yang identik dengan senang-senang yang mereka lakukan. Saat ini gaya hidup mahasiswa cenderung mengikuti trend gaya hidup modern.

Mahasiswa dengan latar belakang ekonomi menengah kebawah kebanyakan juga berkeinginan untuk merasakan hal yang sama dengan mahasiswa yang berasal dari latar belakang ekonomi mapan. Perilaku yang ditampilkan oleh mahasiswa kurang mampu menjadikan mereka bergaya hidup hedonis, karena terbiasa mereka cenderung ingin menjadi pusat perlihatkan dan bergaya layaknya mahasiswa berekonomi menengah keatas mulai dari tempat-tempat terbaru. Kebiasaan yang ditampilkan mahasiswa kurang mampu membuat mereka menjadi terlena dengan kesenangan yang mereka dapat sehingga mereka mencari segala cara demi mndapatkan keinginannya supaya terlihat sama dengan mahasiswa yang memilih ekonomi mapan tanpa memikirkan efeknya lebih lanjut.

Menurut (Febrianti, 2017) mahasiswa yang berperilaku konsumtif memiliki perubahan pada pola hidup mereka, terdapatnya perbedaan antara kebutuhan pokok dan kebutuhan tersier, sehingga menimbulkan dilema antara memenuhi kebutuhan pokok yang sebenarnya lebih penting dari pada pemenuhan gaya hidup. besarnya keinginan yang dimiliki oleh mahasiswa agar mendapatkan pengakuan oleh lingkungan sekitar yang membuat mahasiswa cenderung mengabaikan kebutuhan pokok. Kegiatan membeli sesuatu bukanlah menjadi permasalahan bahkan kegiatan ini sudah menjadi hal yang wajar saja asalkan kegiatan tersebut benar-benar dibutuhkan, yang terjadi pada sekarang ini danmenjadi persoalan adalah ketika membeli suatu barang yang bukan menjadi kebutuhan seseorang, pembelian itu dilakukan karena keinginan yang dikuasai oleh hasrat (wahidah, 2014).

Gaya hidup mahasiswa zaman sekarang bermacam ragam mulai dari pakaian, tas, hingga sepatu yang berlebihan sehingga menimbulkan kegiatan konsumtif oleh mahasiswa. Kegiatan konsumtif yang dilakukan bukan berdasarkan atas kebutuhan melainkan lebih kepada hasrat ataupun hanya sekedar mengikuti trend fashion yang sedang digandrungi oleh teman sepergaulannya (Asmita \& Erianjoni, 2019). Pada kenyataannya yang terjadi saat ini pada mahasiswa Fakultas Ilmu Sosial Universitas Negeri Padang sebagian dari mereka memiliki perilaku konsumtif. Menurut Sumartono (Oktafikasari \& Mahmud, 2017) perilaku konsumtif ialah suatu perilaku memakai produk dilihat dari banyaknya orang dalam memakai produk tersebut. Mahasiswa berperilaku konsumtif didorong oleh hasrat dan keinginan, sehingga mahasiswa mengkonsumsi suatu barang bukan lagi didasarkan pada kebutuhan. Mayoritas perilaku konsumtif mahasiswadapat dilihat dari kebiasaan sehari-hari seoerti nongkrong di cafe, karaoke, shopping serta menghabiskan waktu di luar dari pada mengurusi kuliah. Kenikmatan dan kesenangan dunia yang didapatkan identik dengan gaya hidup hedonis yang membuat mahasiswa menjadi terbiasa bergaya hidup hedonis. Menurut (Martono, 2011) gaya hidup hedonis pada mahasiswa berdampak pada lunturnya peran mahasiswa sebagai agen perubahan (agent of change). Hedonisme juga mengakibatkan mahasiswa berfikir tidak kritis lagi, mereka cenderung melakukan sesuatu tanpa memikirkan efeknya terlebih dahulu, sehingga member efek buruk kepada mahasiswa tersebut seperti mereka sering absen atau tidak masuk dalam kegiatan perkuliahan, bahkan diantara mereka harus mengulang mata kuliah tertentu. Hedonis memiliki makna sebagai sikap acuh terhadap lingkungan sekitar mereka. . paham hedonisme dipelopori oleh Filsuf Epicurus, yang berasumsi bahwa tujuan paling utama dalam hidup adalah mendapatkan kesenangan dan kenikmatan materi yang bertujuan untuk memenuhi kepuasan batin (Simamora, 2014). Gejala hidup hedonis yang makin marak di kalangan mahasiswa memberikan banyak pengaruh buruk terhadap mahasiswa. Gejala gaya hidup hedonis di kalangan mahasiswa Fakultas Ilmu Sosial UNP terlihat pada perilaku sehari-hari mereka seperti gaya berpakaian ke kampus,

\section{Culture \& Society: Journal of Anthropological Research Vol. 1, No. 1, Th. 2019}


tempat nongkrong, serta barang-barang yang dipakai menjadi agenda hidup mereka, dengan gaya hidup yang ditunjukkan mahasiswa tersebut seolah-olah berada pada ekonomi yang mapan.

Hedonisme dapat dianggap baik atau malah sebaliknya tergantung dampak yang didtangkannya. Perilaku hedonis dianggap tidak baik apabila perilaku tersebut mendatangkan penderitaan, kesulitan, dan permasalahan baru yang merugikan orang-orang yang berperilaku seperti ini cenderung menjadikan kesenangan sebgai tujuan hidup (burhanuddin, 1997). Perilaku hedonis sangat menarik bagi mahasiswa. Mereka cenderung untuk memilih hidup mewah, berfoya-foya, dan ingin selalu terlihat berkecukupan tanpa harus bekerja keras. Mahasiswa yang memiliki ekonomi mapan tidak akan mengalami permasalahan, sebaliknya mereka yang berekonomi pas-pasan cenderung selalu berusaha mencari cara agar dapat memenuhi kebutuhannya dengan segala cara, termasuk memilih cara yang salah.

Berdasarkan observasi peneliti terhadap mahasiswa yang ada di Fakultas Ilmu Sosial Universitas Negeri Padang mereka cenderung memiliki bergaya hidup hedonis. Hal tersebut terlihat pada gaya yang ditampilkan sehari-hari dan waktu luang yang dimanfaatkan mereka. Hal ini terbukti dari beberapa informan yang telah peneliti wawancarai mengatakan bahwa tindakan konsumsi yang dilakukan hampir setiap bulan mulai dari shopping, mengunjungi cafe, karoke, hingga pergi jalan-jalan mereka beralasan karena ingin terlihat eksis didepan teman-teman lainnya, mereka sering berbelanja kebutuhan tersier demi terlihat lebih trend di mata temantemannya dan kebanyakan dari informan yang penulis dapatkan mereka berasal dari kalangan keluarga menengah ke bawah dan ada juga berasal dari latar belakang keluarga yang kurang harmonis. Dari wawancara dengan informan, peniliti menemukan bahwa gaya hidup hedonisme yang ditampilkan oleh informan diatas menunjukkan bahwa perbedaan antara pengeluaran dan uang saku yang diterima dari orang tuanya tidak sebanding sehingga menyebabkan mereka memenuhi kebutuhan gaya hidupnya yang hampir sama dengan gaya hidup mahasiswa yang mampu.

\section{Metode Penelitian}

Penelitian ini menggunakan penelitian kualitatif tipe deskriptif. Penelitian kualitatif merupakan penelitian tentang fenomena apa yang dialami oleh subyek penelitian yang berupa perilaku, persepsi, motivasi, tindakan, secara holistik yang dilakukan dengan cara deskriptif dengan memanfaatkan metode alamiah (Lexy J. Moleong, 2017). Tipe penelitian yang digunakan adalah tipe deskriptif. Tipe deskriptif ini memberikan gambaran tentang bagaimana perilaku gaya hidup hedonisme di kalangan mahasiswa kurang mampu FIS UNP. Dengan demikian peneliti akan memperoleh data atau informasi lebih mendalam mengenai fenomena perilaku gaya hidup hedonism di kalangan mahasiswa.

Teknik pemilihan informan yang peneliti gunakan adalah teknik snowball sampling. Maksudnya informan penelitian akan berkembang (bergulir) setelah peneliti berada di lapangan. Untuk jumlah informan yang akan diambil pada dasarnya berdasarkan azas kejenuhan data, artinya tidak ada pembatasan berapa jumlah informan yang akan diambil. Dalam penelitian ini yang menjadi informan kunci adalah RB dan YM. Informan kunci inilah yang memberikan informasi dan saran kepada peneliti untuk menemukan informan selanjutnya. Teknik pengumpulan data yang peneliti gunakan adalah observasi partisipasi pasif, wawancara mendalam dan studi dokumentasi. Penelitian ini dianalisis menggunakan teknik analisis data dari Miles dan Huberman yang terdiri dari reduksi data, penyajian data, dan penarikan kesimpulan.

\section{Hasil dan Pembahasan}

\section{Hasil}

Fakultas Ilmu Sosial (FIS) Universitas Negeri Padang (UNP) merupakan salah satu fakultas yang ada di UNP. Berdasarkan Kepres No. 93/1999 tentang konversi IKIP Padang menjadi

\section{Culture \& Society: Journal of Anthropological Research Vol. 1, No. 1, Th. 2019}


Universitas Negeri Padang. Rektor mengeluarkan SK. No. 176/K12/0T/1999 tentang Penataan Fakultas, Jurusan/Program Studi di lingkungan Universitas Negeri Padang. FIS menyelenggarakan tiga jurusan dan empat program studi kependidikan dan satu program studi non kependidikan. Pada saat sekarang ini Fakultas Ilmu Sosial (FIS) terdiri dari enam jurusan dengan lima program studi kependidikan dan tiga program studi non kependidikan. Program kependidikan terdiri dari Pendidikan Pancasila dan Kewarganegaraan (PPKN), Pendidikan Sejarah, Pendididikan Sosiologi, Pendidikan Geografi, dan yang terbaru pendidikan agama islam (Pendikais) dan tiga program non kependidikan yaitu Program Studi Ilmu Administrasi Negara, geografi, dan penginderaan jauh.

Setelah dilakukannya penelitian diperoleh temuan bahwa gaya hidup hedonis ditujunjukkan pada perilaku mahasiswa dalam menggunakan waktu yang menganggap kesenangan dan kenikmatan adalah tujuan dari hidup mereka. Berdasarkan temuan dilapangan terdapat lima macam gaya hidup yang menggambarkan perilaku hedonisme yang ditampilkan oleh mahasiswa kurang mampu FIS UNP diantaranya:

\section{Shopping}

Shopping merupakan suatu kegiatan berbelanja yang sangat digandrungi oleh wanita. Begitu juga yang terjadi pada mahasiswa yang memiliki keadaan kurang mampu di FIS UNP. Dari hasil penelitian, sebagian besar informan yang diteliti mengatakan bahwa uang yang mereka gunakan untuk aktivitas shopping yang sering dilakukan berasal dari uang bulanan yang dikirim oleh orang tua masing-masing. Kecenderungan mereka dalam berbelanja membuat mereka melakukan kegiatan gali lobang tutup lobang untuk mencukupi kebutuhan selama sebulan. Gaya hidup hedonisme yang dilakukan mereka terlihat pada kebiasaan mereka shopping dimana terlihat konsumtif dalam memanfaatkan uang bulanan mereka. Mereka sering berbelanja suatu barang yang dianggap kurang penting atau kurang dibutuhkan bagi mereka. Tindakan konsumsi yang mereka lakukan semata-mata hanya untuk kesenangan saja bukan berdasarkan faktor kebutuhan melainkan lebih ke pemenuhan kebutuhan hasrat. Mereka bangga jika melakukan kegiatan shopping dengan membeli barang bermerek seperti di toko yang bermerek.

\section{Nongkrong di cafe}

Nongkrong di cafe merupakan kegiatan yan dilakukan disuatu tempat tertentu untuk menghabiskan waktu luang. Fenomena nongkrong ini bahkan sudah menjadi hal yang biasa dan sudah menjadi suatu kebiasaan bagi mahasiswa untuk menghabiskan waktu untuk nongkrong di cafe. Begitu pula yang terjadi pada mahasiswa kurang mampu di FIS UNP. Dari hasil penelitian yang telah dilakukan, umumnya kegiatan nongkrong di cafe dilakukan dengan mengunjungi cafe seperti Cisangkuy, Rubble Shake, Mc'Donald, Pizza Hut. Alasan sebagian besar informan nongkrong di cafe-cafe yang disebutkan diatas hanya untuk pamer. Berdasarkan tuturan dari informan yang telah diteliti mereka lebih sering mengunjungi cafe tersebut pada malam hari, kerena menurut mereka malam hari lebih banyak orang dibandingkan siang. Mereka juga mengatakan kegiatan nongkrong di cafe-cafe tersebut hanya memesan makanan dan minuman yang harganya paling murah, karena yang penting bagi mereka bukan makanannya, tetapi supaya bisa foto-foto di cafe lalu dipamerkan ke media sosial.

\section{Nonton Bioskop}

Bioskop merupakan tempat menonton film. Bioskop diidentik dengan para penonton pada semua kalangan usia.aktivitas menonton film ini digandrungi oleh banyak orang. Sensasi yang dirasakan saat menonton dibioskop berbeda dengan saat menonton TV di rumah. Nonton bioskop merupakan aktivitas yang disenangi mahasiswa FIS UNP terutama pada kalangan mahasiswa kurang mampu. Aktvitas nonton di bioskop ini bahkan sudah menjadi kebiasaan gaya hidup mereka untuk mengisi waktu luang.

\section{Culture \& Society: Journal of Anthropological Research Vol. 1, No. 1, Th. 2019}




\section{Karaoke}

Karaoke merupakan bentuk hiburan dimana seseorang bernyanyi diiringi music dan lirik yang ditampilkan dari layar, rekaman atau discyang berisi rekaman iringan musik dan lirik, digunakan untuk bernyanyi mengiringi music. Aktivitas karaoke bagi mahasiswa merupakan salah satu kegiatan untuk mengusir rasa stress setelah melalui banyak tugas di kampus. Untuk mengusir rasa jenuh beragam cara yang dilakukan mahasiswa, salah satunya yaitu mendatangi tempat karaoke.

\section{Jalan-jalan atau Refreshing}

Jalan-jalan atau refreshing dapat menghilangkan beban pikiran dan kejenuhan yang dirasakan oleh kebanyakan orang saat ini khususnya mahasiswa. Untuk menghilangkan kejenuhan dan stres akibat banyaknya tugas atau kegiatan membuat mahasiswa untuk menenangkan diri salah satunya dengan cara pergi jalan-jalan atau refreshing. Jalan-jalan atau refreshing adalah hal yang biasa bagi setiap orang karena itu dapat mengusir kejenuhan dan rasa bosan. Berbeda halnya dengan mahasiswa zaman sekarang yang lebih banyak menghabiskan waktunya diluar ketimbang melaksanakan kewajibannya sebagai mahasiswa. Hal tersebut juga berlaku pada mahasiswa kalangan kurang mampu di FIS UNP. Kebanyakan dari mereka lebih banyak menggunakan waktu untuk pergi jalan-jalan ketimbang pergi ke kampus. Uang yang seharusnya dipergunakan untuk keperluan dan biaya hidup selama kuliah malah dengan mudah menghabiskan uang untuk hal yang sia-sia, bahkan mereka sering menipu orang tuanya dengan berbagai alasan untuk meminta uang, tak hanya sampai disitu mereka juga berhutang ke temantemannya. Jalan-jalan atau refreshing seperti pergi ke tempat-tempat wisata membuat mereka memiliki kebanggaan dan kesenangan, karena banyak dari mereka yang melakukan ini hanya untuk ajang pamer di media sosial Gaya hidup mereka yang hanya mementingkan kesenangan membuat mereka lupa tentang keadaan ekonomi keluarganya.

\section{Pembahasan}

Berdasarkan observasi yang peneliti lakukan pada perilaku mahasiswa hedonisme di kalangan mahasiswa kurang mampu FIS UNP terlihat bahwa perilaku mahasiswa dalam mengisi waktu mereka habiskan dengan bersenang-senang dan berfoya-foya terutama dalam mengkonsumsi barang atau jasa. Realitas yang dapat dilihat pada mahasiswa di kalangan kurang mampu FIS UNP, bahwa mereka membeli suatu barang hanya melihat simbol ataupun tanda yang melekat pada barang atau jasa itu sendiri (bukan lagi pada kegunaannya) sehingga mereka sebagai konsumen tidak pernah merasa puas dan memicu mereka untuk berkonsumsi secara terus menerus. Barang yang dibeli bukan dianggap sebagai pemenuhan kebutuhan (needs), melainkan untuk pemenuhan hasrat (desire). Kegiatan mahasiswa dalam menghabiskan uang seperti shopping, nongkrong di cafe, karoke, dan jalan-jalan/refreshing menunjukkan bahwa mereka lebih mementingkan kesenangan dunia, sehingga berimbas pada proses perkuliahan, dimana terdapat pengulangan terhadap beberapa mata kuliah dikarenakan jarang masuk kelas pada saat perkuliahan berlangsung. Alasan mereka bergaya hidup seperti itu juga dipengaruhi oleh lingkungan yang lebih mengutamakan kepentingan untuk kesenangan hidup ketimbang memikirkan kuliah. Mereka merasa malu jika tidak mengikuti trend anak zaman sekarang sekaligus dijadikan sebagai ajang pamer terhadap barang-barang dan aktifitas yang dilakukan.

Sesuai dengan fokus penelitian mengenai perilaku gaya hidup hedonisme di kalangan mahasiswa kurang mampu Fakultas Ilmu Sosial Universitas Negeri Padang relevan apabila dianalisis dengan teori masyarakat konsumsi yang dikemukakan oleh Jean Baudrillard. Relevansi dari teori tersebut adalah mahasiswa Fakultas Ilmu Sosial Universitas Negeri Padang mengkonsumsi barang-barang bukan lagi sekedar untuk pemenuhan kebutuhan dasar saja melainkan lebih kepada hasrat untuk memiliki sesuatu. Jean Baudrillard dalam teori masyarakat 
konsumsi menyatakan bahwa perilaku mengkonsumsi barang atau jasa tidak hanya didasarkan pada manfaat melainkan lebih menekankan pada symbol yang melekat pada barang dan jasa (Demartoto, 2009). Rasionalnya seseorang melakukan kegiatan konsumsi terhadap barang atau jasa tanpa adanya pertimbangan, melainkan hanya melihat citra yang melekat pada barang atau jasa (anandita, 2014). Hal inilah yang dialami oleh mahasiswa yang berasal dari kalangan kurang mampu di FIS UNP sekarang ini. Kebiasaan bersenang-senang dan berfoya-foya yang dilakukan oleh mahasiswa tersebut hanya untuk terlihat sama dan tidak dikatakan ketinggalan zaman oleh teman-temannya. Untuk memenuhi gaya hidup seperti teman-temannya mereka harus mencukupi kebutuhan tersebut dengan cara lain seperti berhutang ke teman-temannya, melakukan pinjaman online serta menggadaikan apapun barang-barang elektronik yang dimiliki agar kebutuhan terpenuhi dan bisa mengikuti trend terkini.

\section{Kesimpulan}

Berdasarkan hasil penelitian yang telah peneliti lakukan di Fakultas Ilmu Sosial (FIS) Universitas Negeri Padang (UNP) peneliti melihat bahwa adanya kecenderungan mahasiswa dalam gaya hidup hedonisme yang di tampilkan khususnya pada mahasiswa yang memiliki latar belakang ekonomi pas-pasan. Hal ini dibuktikan dalam perilaku yang ditampilkan oleh mahasiswa seperti shopping, nongkrong di cafe, nonton bioskop, karaoke, dan jalan-jalan. Uang belanja yang dikirim oleh orang tua lebih banyak dimanfaatkan untuk hura-hura ketimbang untuk keperluan kuliah. Terdapat lima perilaku yang ditampilkan mahasiswa dengan gaya hidup hedonisme yaitu: (1) shopping, (2) nongkrong di cafe, (3) nonton bioskop, (4) karaoke, dan (5) jalan-jalan. Untuk mendapatkan kesenangan dunia ini rata-rata mereka melakukan berbagai macam untuk mendapatkan uang seperti dengan cara berhutang, menggadaikan dan menjual barang-barang yang dimiliki, serta mereka berbohong kepada orang tua untuk meminta uang dengan alasan untuk keperluan kuliah. Dengan gaya hidup yang lebih mementingkan kesenangan dunia berimbas kepada perkuliahan mereka seperti ttidak masuk dalam perkuliahan yang menyebabkan harus mengulang beberapa mata kuliah.

\section{Daftar Pustaka}

Anandita, devi. (2014). Konsumsi Tanda Pada Fashion Hijab.

Asmita, D., \& Erianjoni. (2019). perilaku konsumtif mahasiswi dalam mengikuti trend fashion masa kini (studi kasus mahasiswi sosiologi fis UNP). Perspektif, 2(2), 91-96.

Burhanuddin. (1997). Logika Materiil Filsafat Ilmu Pengetahuan. jakarta: rineka cipta.

Demartoto, A. (2009). Membedah Gagasan Post Modernisme Baudrillard Realitas Semu. Journal.

Destiana, I. (2018). Gaya hidup hedonis di kalangan mahasiswa penerima bidikmisi unp.

Febrianti, C. (2017). Gaya Hidup Hedonisme Mahasiswa Universitas Riau Di Kelurahan Simpang Baru Kecamatan Tampan Kota Pekanbaru. Journal.

Lexy J. Moleong. (2017). Metode Penelitian Kualitatif. bandung: PT. Remaja Rosdakarya.

Lukitsari, V. (2016). Studi Tentang Gaya Hidup Hedonisme Pada Mahasiswa Fakultas Bahasa Dan Seni Universitas Negeri Surabaya Angkatan Tahun 2012-2013. Journal.

Martono, N. (2011). Sosiologi Perubahan Sosial. jakarta: PT. Rajagrafindo Persada.

Nisrima, S., Muhammad, Y., \& Erna, H. (syiah kuala niversity. (2016). pembinaan perilaku sosial remaja penghuni yayasan islam media kasih kota Banda Aceh. Jurnal Ilmiyah Mahasiswa Pendidikan Kewarganegaraan Unsyiah, 1(1), 192-204.

Nur ambadra dewi. (2018). GAYA HIDUP HEDONIS PADA MAHASISWA.

Oktafikasari, E., \& Mahmud, A. (2017). Konformitas Hedonis dan Literasi Ekonomi Terhadap Perilaku Konsumtif Melalui Gaya Hidup Konsumtif. Economic Education Analysis Journal, 6(3), 684-697.

Riadhah, C. A., \& Rachmatan, R. (2016). Perbedaan Konsumsi Hedonis pada Mahasiswa 
Universitas Syiah Kuala Ditinjau dari Jenis Kelamin dan Asal Fakultas. Psympathic: Jurnal Ilmiah Psikologi, 3(2), 179-190. https://doi.org/10.15575/psy.v3i2.1109

Simamora, J. (2014). . Perilaku Hedonisme Di Kalangan Mahasiswa (Studi Deskriptif Pada Mahasiswa Fakultas Ilmu Sosial dan Ilmu Politik Universitas Sumatera Utara). Skripsi.

Trimartati, N. (2014). Studi Kasus Tentang Gaya Hidup Hedonisme Mahasiswa Bimbingan Konseling Universitas Ahmad Dahlan. Journal, 3 no 1.

Wahidah, nurul. (2014). Pengaruh Perilaku Konsumtif Terhadap Gaya Hidup Mahasiswa Pendidikan Ekonomi FKIP Untan. Jurnal Pendidikan Dan Pembelajaran, 3(2). 